\title{
Separating Hope from Hype: Some Ethical Implications of the Development of Deep Brain Stimulation in Psychiatric Research and Treatment
}

\author{
Thomas E. Schlaepfer, MD, S.H. Lisanby, MD, and Stefano Pallanti, MD, PhD
}

\section{INTRODUCTION}

Major depression is the most common serious brain disorder with a lifetime prevalence of up to $17 \% .^{1}$ Despite numerous options currently available for the treatment of depression, $\sim 2$ million people in the United States may experience an inadequate response to treatment (treatment-resistant depression [TRD]) at some point in their lives. ${ }^{2}$ The definition of TRD is variable, ranging from a failure to respond to two or more trials of antidepressant monotherapy to a failure to respond to four or more trials of different antidepressant therapies, including augmentation, combination therapy, and electroconvulsive therapy. ${ }^{3}$ It has been reported that as many as one-third of patients experience only a partial response to initial therapy, while nearly one-fifth are considered nonresponders. ${ }^{4}$ In addition to the obvious quality of life issues for the patient with TRD, the economic cost of TRD is significant. Annual healthcare costs increase significantly for patients with TRD with each successive change in antidepressant medication. Early in treatment (two medication changes), the annual costs are $<\$ 7,000 /$ year. ${ }^{5}$ By the eighth medication change, annual costs double to nearly $\$ 14,000 /$ year. $^{5}$

There is a well-documented need for better long-term treatments for TRD, as witnessed by multiple efforts to establish treatment algorithms and best treatment steps when first and subse- quent treatment measures prove inadequate. ${ }^{6}$ The Sequenced Treatment Alternatives to Relieve Depression (STAR*D) study, which analyzed outcome following several standardized antidepressive treatment steps, reported that $33 \%$ of patients did not respond even after four evidencebased treatment steps. ${ }^{7}$ A substantial proportion of patients are inadequately treated and some of these will go on to suffer from chronic, debilitating, and life-threatening symptoms. For those patients, other therapeutic options must be considered. Different neuromodulatory approaches beyond electroconvulsive therapy (ECT) are being researched and have been demonstrated to show some promise in TRD. ${ }^{8}$ Somatic interventions may offer hope to people who are unable to control their depression with pharmacotherapy and/ or cognitive behavioral therapy.

\section{THE HOPE OF BRAIN STIMULATION THERAPIES}

Neuromodulation techniques have been part of psychiatry since the introduction of ECT some 80 years ago. In the last decades technologies such as transcranial magnetic stimulation, magnetic seizure therapy, vagus nerve stimulation, and deep brain stimulation (DBS) have been researched in terms of putative applicability in psychiatric therapy..$^{9,10}$ First evidence for efficacy of DBS has been demonstrated in studies of

Dr. Schlaepfer is Vice Chair and Professor of Psychiatry and Psychotherapy at University of Bonn in Germany and Associate Professor of Psychiatry and Mental Health at the Johns Hopkins University, Baltimore, MD. Dr. Lisanby is Professor of Clincal Psychiatry and Director of the Brain Stimulation Division at Columbia University/New York State Psychiatric Institute in New York, NY. Dr. Pallanti is Associate Professor of Psychiatry at University of Florence in Italy and Adjunct Professor at Mount Sinai School of Medicine in New York, NY.

Faculty Disclosures: Dr. Schlaepfer is Chair of the World Federation of Societies of Biological Psychiatry (WFSBP) Task Force on Brain Stimulation and Co-Chair of the WFSBP Task Force on ECT. Dr. Lisanby chairs the APA Task Force on ECT and has received research support from Advanced Neuromodulation Systems/Saint Jude, Brainsway, Cyberonics, Fisher, Magstim, Magventures, and Neuronetics. She is coinventor on a patent application filed by Columbia University for TMS technology. 
treatment-refractory psychiatric diseases, such as obsessive-compulsive disorder ${ }^{11-13}$ and major depression. ${ }^{14-16}$ In fact, psychiatric DBS is already moving from experimental to clinical use. This is evidenced by the growing number of worldwide DBS implantations in neuropsychiatric cases, the increasing amount of publications presenting outcome data, ${ }^{17}$ and the fact that two large pivotal trials of DBS for major depression have been launched recently. ${ }^{18,19}$ In DBS for major depression, three groups using different stimulation sites reported comparable response rates of about $50 \%$. This is surprising and unexpected since the patients studied did not respond to up to 45 adequate therapeutic trials using psychotherapy, pharmacotherapy, and $\mathrm{ECT}^{14}$; and might well reflect one of the most treatment-resistant patient population studied so far.

\section{SOME ETHICAL ISSUES}

While these early results are very promising, invasive neurosurgery in highly vulnerable patients poses different ethical questions than the application of DBS for neurological disorders. Ethical analyses of psychiatric DBS are still rare and have mostly focused on the high vulnerability of psychiatric patients or the haunting history of psychosurgery. Given the quickly increasing interest in DBS research for neuropsychiatric disorders, investigators, investigational review boards, psychiatrists, patients, and caregivers are obviously in need of clear criteria that can easily be applied to both research and clinical decision-making. Although most current ethical perspectives provide a well-nuanced perspective on psychiatric DBS, ${ }^{20,21}$ some of them still draw on references to early psychosurgery ${ }^{22,23}$ or the risk to alter a patient's personality ${ }^{20,24}$ to delineate limitations for ethically legitimate psychiatric DBS.

However, both references seem to be misleading. The reference to psychosurgery is misleading as psychiatric DBS does not stand in a continuous line with early psychosurgery (it was adopted from the field of pain therapy and movement disorders treatment) and as it differs from psychosurgery in almost all important ethical variables. ${ }^{25}$ The potential risk of DBS-induced personality changes cannot be taken as an ethical criterion to mark ethical limitations of psychiatric DBS. Modification of mood and cognitive behavior - and thus important elements of personality - is not an unwanted, coincidental side effect, but rather the main intended outcome of this intervention. ${ }^{25}$
Until large-scale studies in psychiatric DBS are more feasible, an increasing amount of single case studies is being published. DBS efficacy in single cases has been reported for a large variety of different mental and behavioral states, eg, obesity, ${ }^{26,27}$ alcohol addiction, ${ }^{28}$ memory enhancement, ${ }^{26}$ impulsive violent behavior, ${ }^{29}$ or self-mutilating behavior. ${ }^{30}$ While these are certainly noteworthy results, we must ask how many cases that failed to show any efficacy have never been published? While the risk of selective reporting is by no means unique to DBS, because so much of this work has been done through the reporting of single subject case reports, the field is particularly vulnerable to this publishing bias. Until cohort studies are routinely done in neuropsychiatric DBS, the possibility always exists that only the "best and the brightest" results make their way into print, at the expense of negative data which might also have a story to tell. This distortion poses a risk to the reliability of reported data and thus to the sustainability of this nascent field. ${ }^{31}$

\section{RESPONSIBLE REPORTING}

In addition, it is an ethical requirement to help patients, their relatives, and the public at large to separate solid data from hype. Scientists need to consider not only DBS treatment and patient care, but also the portrayal of DBS in the public or to psychiatric patients contemplating DBS in the future. Public events informing Parkinson or tremor patients, their relatives, and the public about DBS sometimes risk conveying mainly treatment benefits by presenting patients with large motor and quality of life improvement who report about the treatment success and have not experienced any adverse event. In contrast, short-, medium- or long-term adverse events, eg, hemorrhages, dysarthria, psychosocial misadjustments, ${ }^{32}$ or insufficient treatment responses are hardly ever reported in such a demonstrative and intriguing way, eg, by displaying computed tomography scans or by inviting patients who have experienced complications.

Since the heterogeneous outcomes after DBS are not adequately presented, the public and patients are misled and information meetings might turn, deliberately or inadvertently, into promotional events. Considering the higher vulnerability and sometimes restricted autonomy capacity in psychiatric patients, the call for balanced information is warranted. The problem of 
uncritically positive media reporting is certainly not specific to psychiatric DBS, yet it is particularly worrisome in this field as well-established institutional review board criteria for regulating DBS trials are still lacking and media reporting of DBS effects has shown to be overly optimistic, already omitting major risks and problems. ${ }^{33}$ Thus, ethical guidelines are required not just for DBS application in research and treatment, but also for publishing clinical results of DBS.

\section{CONCLUSION}

DBS might turn out to be a focused and efficacious treatment option for carefully selected psychiatric patients resistant to traditional methods and maybe in the future for those patients who show a significant, yet still insufficient effect to other treatments. There are no inherent ethical objections; the same ethical criteria that are already widely used to assess other biomedical interventions can be productively applied for analyzing DBS studies and for clinical decision-making. However, these criteria pose several specific challenges to psychiatric DBS, illustrating that the time is not yet ripe for widespread clinical application. This is due not only to the current scarcity of convincing clinical outcome data, but also to the currently unmet ethical requirements.

A particularly strict and highly careful weighing of potential benefits, risk of serious adverse events, and patient's preferences has to be performed for each patient on an individual basis. However, if we do our ethical homework conscientiously, confirm the favorable efficacy to side effect profile in larger and better controlled studies, learn from earlier mistakes in DBS for neurological indications (like the early focus on outcome scores only, leaving aside broader treatment effects on quality of life), and implement specific procedural safeguards, DBS certainly has the potential to become a promising and legitimate treatment approach for some of the most disabling disorders known to humanity. CNS

\section{REFERENCES}

1. Kessler RC, Berglund P, Demler O, Jin R, Merikangas KR, Walters EE. Lifetime prevalence and age-of-onset distributions of DSM-IV disorders in the National Comorbidity Survey Replication. Arch Gen Psychiatry. 2005;62:593-602.

2. Nierenberg AA, Papakostas GI, Petersen T, et al. Lithium augmentation of nortriptyline for subjects resistant to multiple antidepressants. J Clin Psychopharmacol. 2003;23:92-95.

3. Philip NS, Carpenter LL, Tyrka AR, Price LH. Pharmacologic approaches to treatment resistant depression: a re-examination for the modern era. Expert Opin Pharmacother. 2010;11:709-722.
4. Fava M, Davidson KG. Definition and epidemiology of treatment-resistant depression. Psychiatr Clin North Am. 1996;19:179-200.

5. Russell JM, Hawkins K, Ozminkowski RJ, et al. The cost consequences of treatment-resistant depression. J Clin Psychiatry. 2004;65:341-347.

6. Rush AJ, Sackeim HA, Marangell LB, et al. Effects of 12 months of vagus nerve stimulation in treatment-resistant depression: a naturalistic study. Biol Psychiatry. 2005;58:355-363

7. Rush AJ, Trivedi MH, Wisniewski SR, et al. Acute and longer-term outcomes in depressed outpatients requiring one or several treatment steps: a STAR* ${ }^{*}$ report. Am J Psychiatry. 2006;163:1905-1917

8. Holtzheimer PE, Nemeroff CB. Novel targets for antidepressant therapies. Curr Psychiatry Rep. 2008;10:465-473.

9. Schlaepfer TE, George MS, Mayberg H. WFSBP Guidelines on Brain Stimulation Treatments in Psychiatry. World J Biol Psychiatry. 2009:1-17.

10. Schlapfer TE, Bewernick BH. Deep brain stimulation for psychiatric disorders--state of the art. Adv Tech Stand Neurosurg. 2009;34:37-57.

11. Mallet L, Polosan M, Jaafari N, et al. Subthalamic nucleus stimulation in severe obsessive-compulsive disorder. N Engl J Med. 2008;359:2121-2134.

12. Abelson JL, Curtis GC, Sagher 0, et al. Deep brain stimulation for refractory obsessive-compulsive disorder. Biol Psychiatry. 2005;57:510-516.

13. Greenberg BD, Malone DA, Friehs GM, et al. Three-year outcomes in deep brain stimulation for highly resistant obsessive-compulsive disorder. Neuropsychopharmacology. 2006;31:2394.

14. Bewernick B, Hurlemann R, Matusch A, et al. Nucleus Accumbens Deep Brain Stimulation Decreases Ratings of Depression and Anxiety in Treatment-Resistant Depression. Biol Psychiatry. 2009;67:110-116.

15. Lozano AM, Mayberg HS, Giacobbe P, Hamani C, Craddock RC, Kennedy SH. Subcallosal cingulate gyrus deep brain stimulation for treatment-resistant depression. Biol Psychiatry. 2008:64:461-467.

16. Malone DA, Jr., Dougherty DD, Rezai AR, et al. Deep Brain Stimulation of the Ventral Capsule/Ventral Striatum for Treatment-Resistant Depression. Biol Psychiatry. 2009;65:267-275.

17. Goodman WK, Insel TR. Deep brain stimulation in psychiatry: concentrating on the road ahead. Biol Psychiatry. 2009;65:263-266.

18. Advanced Neuromodulation Systems (ANS) Inc. BROADEN Clinical Study. A Study of a Non-Pharmacological Device for Depression. 2007; http://www.broadenstudy. com/sb/index.html. Accessed: January 6, 2009.

19. Medtronic Inc. Medtronic to Pursue Major Clinical Trial of Deep Brain Stimulation as Depression Treatment. 2006; http://findarticles.com/p/articles/mi_m0EIN/is_ 2006_April_25/ai_n26838044?tag=content-inner;col1. Accessed: January 6, 2009.

20. Glannon W. Stimulating brains, altering minds. J Med Ethics. 2009;35:289-292.

21. Rabins P, Appleby B, Brandt J, et al. Scientific and Ethical Issues Related to Deep Brain Stimulation for Disorders of Mood, Behavior and Thought. Arch Gen Psychiatry. 2009;66:931-937.

22. Kringelbach ML, Aziz TZ. Deep brain stimulation: avoiding the errors of psychosurgery. JAMA. 2009;301:1705-1707.

23. Miller G. Neuropsychiatry. Rewiring faulty circuits in the brain. Science. 2009:323:1554-1556

24. Hildt E. Electrodes in the brain: Some anthropological and ethical aspects of deep brain stimulation. International Review of Information Ethics. 2006;5:33-39.

25. Synofzyk M, Schlaepfer TE. Stimulating personality: Ethical criteria for deep brain stimulation in psychiatric patients and for enhancement purposes. J Biotechnol. 2008;3:1511-1520

26. Hamani C, McAndrews MP, Cohn M, et al. Memory enhancement induced by hypothalamic/fornix deep brain stimulation. Ann Neurol. 2008;63:119-123.

27. Sani S, Jobe K, Smith A, Kordower JH, Bakay RA. Deep brain stimulation for treatment of obesity in rats. J Neurosurg. 2007;107:809-813.

28. Kuhn J, Lenartz D, Huff W, et al. Remission of alcohol dependency following deep brain stimulation of the nucleus accumbens: valuable therapeutic implications? J Neurol Neurosurg Psychiatry. 2007;78:1152-1153.

29. Franzini A, Marras C, Ferroli P, Bugiani O, Broggi G. Stimulation of the posterior hypothalamus for medically intractable impulsive and violent behavior. Stereotact Funct Neurosurg. 2005;83:63-66.

30. Kuhn J, Lenartz D, Mai JK, Huff W, Klosterkoetter J, Sturm V. Disappearance of self-aggressive behavior in a brain-injured patient after deep brain stimulation of the hypothalamus: technical case report. Neurosurgery. 2008;62:E1182.

31. Schlaepfer TE, Fins JJ. Deep brain stimulation and the neuroethics of responsible publishing: when one is not enough. JAMA. 2010;303:775-776.

32. Schupbach M, Gargiulo M, Welter ML, et al. Neurosurgery in Parkinson disease: a distressed mind in a repaired body? Neurology. 2006;66:1811-1816.

33. Racine E, Waldman S, Palmour N, Risse D, Illes J. "Currents of hope": neurostimulation techniques in U.S. and U.K. print media. Camb Q Healthc Ethics. 2007;16:312-316. 